approach to the public health. In Turkey, the health transformation program for the development of healthcare services was initiated in 2002 and primary health care services were prioritised. Also within this scope, the OSH Department of Public Health Institution of Turkey (PHIT) is actively involved with occupational health since 2011. In addition, after the law enacted in 2012, Community Health Centres (CHC) serving under the PHIT started to give OSH services to the sector. Smaller companies hire OSH services from a private organisation or from a CHC (currently 84 out of 900 CHCs provide OSH services). Family physician system has been introduced, and as of today, approximately 23000 family physician are widely available throughout the country. The fight against chronic diseases is at the main agenda of Turkey. Surveillance studies for awareness, data collection, analysis and prevention and protection are also continuing, especially in primary health care services. Taking advantage of the knowledge and experience of international studies with the public health approach and sharing our own experiences will contribute to the worldwide OSH services.

\section{$1701 \mathrm{~h}$ WORK-RELATED PROBLEMS. WHAT CAN GENERAL PRACTITIONERS IN THE NETHERLANDS DO?}

${ }^{1}$ Paul Smits*, ${ }^{2}$ Carel Hulshof, ${ }^{3}$ Marjolein Bastiaanssen, ${ }^{4}$ Jacintha van Balen. ${ }^{1}$ Occupational physician, Centre for evidence-based education, Academic Medical Centre (AMC), Amsterdam, The Netherlands; ${ }^{2}$ Occupational physician, professor in Occupational Medicine, Coronel Institute of Occupational Health, Academic Medical Centre (AMC), Amsterdam, The Netherlands; coordinator guidelines, Netherlands Society of Occupational Medicine (NVAB); ${ }^{3}$ Occupational physician, Netherlands Society of Occupational Medicine (NVAB), The Netherlands; ${ }^{4}$ General practitioner, Dutch College of General Practitioners (NHG), Netherlands Lisette Verlee, general practitioner (NHG)

\subsection{6/oemed-2018-ICOHabstracts.1194}

Background Having a job is a health-promoting factor, but when a job is performed in unsafe or unhealthy conditions, it can lead to adverse symptoms or disorders. Often, patients go to their general practitioner (GP) first. Giving attention to work and health is a task for both the GP and the occupational physician (OP).

In 2014 the Dutch College of General Practitioners (NHG) and the Netherlands Society of Occupational Medicine (NVAB) signed a declaration about work and health which stated that general practitioners and occupational physicians, in the interest of patients - in good cooperation - will contribute to help people enter, stay in or return to appropriate work. The project also links with the common pledge, also in 2014, of The World Organisation of Family Doctors (WONCA) and the International Commission on Occupational Health (ICOH) to better integrate occupational health in the primary care setting, to the benefit of all workers and their families.

Aim To incorporate 'work and health' in general practice guidelines, the NHG and NVAB developed a guidance document. Next step is to promote that general practitioners give more attention to occupation and work.

Method We developed a workshop to recognise work-related health problems. Four main issues are discussed:

- Ask for a patient's occupation
- Identify and diagnose work-related health problems

- Consider the consequences of chronic diseases of adolescents for their career choice

- Collaborate with occupational physicians in case of workrelated health problems

Results This workshop has been conducted twice in the Netherlands and once at WONCA Europe (June 2017) and it was evaluated positively.

Message Attention for work and health is important for a GP. Recognition and diagnosis of work-related health problems is a GP task to be supported by education and training.

\section{Radiation}

\section{ALL OF US AT RISK? HOW TO ACCESS THE HAZARDOUSNESS OF ELECTROMAGNETIC FIELDS}

Claudine Neumann*, Marc Wittlich. Institute for Occupational SafetyandHealth of the German Social Accident Insurance, Sankt Augustin, Germany

\subsection{6/oemed-2018-ICOHabstracts. 1195}

Introduction Electromagnetic fields (EMF) are everywhere. Most of our technology today and in future is based upon applications using electric currents, magnets and thus bear the risk to emit hazardous levels of electromagnetic fields. For this purpose workplace exposure due to EMF has to be assessed to ensure that impermissible exposure of employees is avoided. Particular attention has to be paid to employees with medical implants. Our presentation focusses on the process of exposure assessment of electromagnetic fields at several industrial workplaces.

Methods Commonly measurements are performed to assess electromagnetic fields at workplace. Electromagnetic field simulations via numerical calculations can be needful if the EMF source is very complex or direct measurement is not possible. Measurements require a high degree of expert knowledge to assess the entire exposure scenario: relevant field sources have to be identified with both knowledge of fundamental functionality and operating frequency. Risk assessment usually considers working procedures and the whole working area at large. Results Several industrial applications imply a potential risk for safety and health of employees at their workplace. Thus, exposure has to be minimised by either technical, organisational and/or personal measures. Most of the required measures are simple as well as inexpensive, e.g. provision of operating instructions, safety instructions of employees, labelling of critical areas or just increase of distance to the field source. Only few cases require extensive measures, which may lead to a prohibition to resume work - especially for employees with active implants.

Discussion EMF at workplace are underestimated and somehow neglected in the scope of risk assessment. That's why people have to become sensitised to this topic to recognise possible hazards.

Especially employees with medical implants are particularly vulnerable with regard to EMF. For this purpose a specially tailored risk assessment procedure is needed to address this problem completely and more adequate. 